\title{
Midlife Cardiovascular Status and Old Age Physical Functioning Trajectories in Older Businessmen
}

\section{von Bonsdorff, Mikaela B.}

2019-12

von Bonsdorff , M B , Haapanen, M J , Törmäkangas , T, Pitkälä , K H , Stenholm , S \& Strandberg , T E 2019 , ' Midlife Cardiovascular Status and Old Age Physical Functioning Trajectories in Older Businessmen ' , Journal of the American Geriatrics Society , vol. 67 , no. 12 , pp. 2490-2496 . https://doi.org/10.1111/jgs.16150

http://hdl.handle.net/10138/318485

https://doi.org/10.1111/jgs. 16150

acceptedVersion

Downloaded from Helda, University of Helsinki institutional repository.

This is an electronic reprint of the original article.

This reprint may differ from the original in pagination and typographic detail.

Please cite the original version. 
Word count Main text: 2999 Jyväskylä, Jyväskylä, Finland University Hospital, Helsinki, Finland Finland Turku, Finland

\section{Correspondence}

University of Jyväskylä

PO Box 35

Fl-40014 University of Jyväskylä

\section{M idlife cardiovascular status and old age physical functioning trajectories in older business men}

Mikaela B. von Bonsdorff, PhD a,b , Markus J. Haapanen, BM b,c, Timo Törmäkangas, PhDa , Kaisu H. Pitkälä MD, PhDc, Sari Stenholm, PhD ${ }^{d, e}$, Timo E. Strandberg, MD, PhD f,g

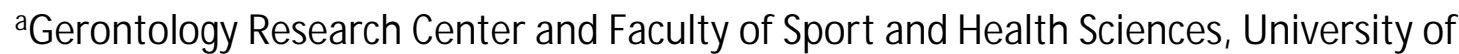

bFolkhälsan Research Center, Helsinki, Finland

'Department of General Practice and Primary Health Care, University of Helsinki and Helsinki

dDepartment of Public Health, University of Turku and Turku University Hospital, Turku,

eCentre for Population Health Research, University of Turku and Turku University Hospital,

fUniversity of Helsinki, Clinicum and Helsinki University Hospital, Helsinki, Finland

gCentre for Life Course Health Research, University of Oulu, Oulu, Finland

Mikaela von Bonsdorff, PhD, Associate Professor

Gerontology Research Center and Faculty of Sport and Health Sciences

Tel. +358 400342 692, E-mail mikaela.vonbonsdorff@jyu.fi

Running head: Cardiovascular health and physical functioning trajectories 


\section{ABSTRACT}

Background. The associations between cardiovascular disease (CVD) risk and later physical functioning have been observed, but few studies with follow-up into old age exist. We investigated the association between cardiovascular status in midlife and physical functioning trajectories in old age.

Methods. In the Helsinki Businessmen Study cohort (Caucasian men born in 1919-1934) three CVD status groups were formed based on clinical measurements carried out in 1974: signs of CVD (diagnosed clinically or with changes in ECG, chronic disease present or used medication, $n=563)$; healthy and low CVD risk ( $n=593)$ and high CVD risk $(n=1222)$. Of them, 1560 men had data on physical functioning from at least one of four data collection waves between 20002010. Ten questions from the RAND-36 (SF-36) survey were used to construct physical functioning trajectories with latent class growth mixture models. M ortality was accounted for in competing risk models.

Results. A five-class solution provided the optimal number of trajectories: 'intact', 'high stable', 'high and declining', 'intermediate and declining' and 'consistently low' functioning. Compared to low CVD risk, high CVD risk in midlife decreased the risk of being classified into the 'intact' (fully adjusted $\beta-3.98$, SE $2.0, p=0.046$ ) relative to 'consistently low' physical functioning trajectory. Compared to low CVD risk, those with signs of CVD were less likely to follow the 'intact', 'high stable' or 'high and declining' relative to the 'consistently low' trajectory (all $\mathrm{p} \varangle 0.018)$

Conclusions. Among businessmen, a more favorable CVD profile in midlife was associated with better development of physical functioning in old age.

Key words: Cardiovascular health, physical functioning trajectories, growth mixture model, life course epidemiology, healthy ageing 
64

65

66

67

68

69

71

72

73

74

75

76

77

78

79

80

81

82

83

84

85

86

\section{INTRODUCTION}

Adequate physical functioning is important in maintaining independence and quality of life with advancing age. ${ }^{1}$ Associations between poor physical functioning and adverse outcomes such as geriatric syndromes, nursing home admission and premature mortality ${ }^{2-6}$ stress the importance of identifying modifiable risk factors in time. Knowledge on these risk factors may help in designing interventions aimed at maintaining the ability to actively engage in society and live independently. ${ }^{7}$

Evidence from longitudinal studies suggests that individual modifiable cardiovascular risk factors such as high blood pressure and cholesterol, smoking, obesity and hyperglycemia are linked with later physical functioning.-12 While the association of clusters of three or four CVD risk factors ${ }^{13-15}$ and established composite CVD risk indices ${ }^{16-19}$ and later physical functioning measures have been studied, only few studies with follow-up from midlife into old age exist. ${ }^{15,16,18,19}$ Furthermore, little is known about whether and how midlife cardiovascular status is associated with various trajectories of physical functioning in old age. There is marked heterogeneity in the progression of physical functioning with advancing age $\mathrm{e}^{20}$ and it is influenced by current, but also past risk factors. More information on early risk factors for patterns of physical functioning in older age would provide insight into more targeted promotion of functioning. We investigated the association between modifiable midlife cardiovascular risk factors measured in the year 1974 and physical functioning trajectories in old age, which had been assessed at four time points over a 10-year period between 2000 and 2010. 
88

89

90

91

92

\section{MATERIALS AND METHODS}

\section{Study population}

The Helsinki Businessmen Study (HBS) cohort has been described in detail earlier. ${ }^{21}$ Briefly, the present study population consisted of white men born between 1919 and 1934 . They shared a similar working status and belonged to the highest socioeconomic class. Between the years 1964 and 1973, 3490 men participated in voluntary health check-ups at the Finnish Institute of Occupational Health that included measurements on CVD risk factors which were considered to be important at that time. Of these men, 3309 formed the baseline cohort for later examinations, see Figure 1. During the years 1972-73 these men were screened for eligibility for a CVD primary prevention trial and in 1974, 1222 men were assessed as having high or low CVD risk or signs of CVD (see below for definitions of CVD risk). ${ }^{21}$ During 1974-1980, 1222 high CVD risk men participated in a multifactorial prevention trial, ${ }^{22}$ but participation in the trial did not affect the present analyses and all men were included to improve statistical power. Of the 2378 men who had data on CVD status in 1974, 1560 had data on physical functioning from at least one of the four subsequent data collection waves carried out in the years 2000, 2003, 2007 and 2010 (response rates were $81.5 \%, 66.3 \%, 65.1 \%, 67.8 \%$, respectively) and they formed the analytical sample of this study. The follow-up studies of the HBS have been approved by the Ethics Committee of the Department of Medicine, Helsinki University Hospital, Finland and the study has been registered as Clinical Trials.gov identifier: NCT02526082.

\section{Cardiovascular status and risk definitions in midlife}

Examinations for CVD risk factors and health status were carried out in 1974 at a mean age of 47.3 (SD 4.0) years. Overweight was determined by relative body weight (\%) (body weight in kilograms x 100 divided by height in centimeters minus 105). ${ }^{23}$ Smoking was inquired in a 
112 questionnaire asking how many cigarettes per day they smoked. Blood pressure was measured

113 in a sitting position after 10 min rest using a mercury sphygmomanometer. Fasting serum

114 cholesterol and triglycerides were measured using standard methods. Blood glucose ( $\mathrm{mmol} / \mathrm{L}$ )

115 was measured 1 hour after a glucose load of $1 \mathrm{~g} / \mathrm{kg}$ of body weight administered orally. Resting

116 and exercise electrocardiograms were taken at the laboratory and medical history was

117 recorded. In 1974, cohort members were classified into groups according to risk factors and

118 possible signs of CVD and other chronic diseases. ${ }^{22}$ The CVD risk factors and cut-offs were 119 defined as follows: 1 ) relative body weight $\geq 120 \%$ (corresponds to $\mathrm{BM} I \geq 27.8 \mathrm{~kg} / \mathrm{m}^{2}$ ); 2 ) smoking

$120>10$ cigarettes/day; 3) blood pressure $\geq 160 / 95 \mathrm{mmHg}$; 4) serum cholesterol $\geq 7.0 \mathrm{mmol} / \mathrm{L}$

121 (corresponds to $6.4 \mathrm{mmol} / \mathrm{L}$ with current laboratory methods); 5) serum triglycerides $\geq 1.7$

$122 \mathrm{mmol} / \mathrm{L}$; and 6) 1-hour post-load glucose $\geq 9.0 \mathrm{mmol} / \mathrm{L}^{22}$ The distribution of risk factors in our

123 analytical sample (according to cut-offs described above) was as follows: $41.4 \%$ had one, $32.2 \%$

124 had two, $17.0 \%$ had three and $9.4 \%$ four or more CVD risk factors. It is of note that risk

125 definitions reflected the situation in the 1970's. Albeit according to current standards, low-risk

126 men would rather be defined to be at "intermediate" risk, we wanted to use the original CVD

127 grouping that has been reported in several papers. ${ }^{22,24}$

128

129 Three CVD status groups were formed: 1 ) low CVD risk ( $n=593$, healthy, no signs of CVD, none 130 of the aforementioned risk factors); 2 ) high CVD risk ( $n=1222$, healthy, no signs of CVD, but had

131 at least one of the CVD risk factors, mean 2.1 risk factors); and 3) signs of CVD ( $n=563$, CVD 132 diagnosed either clinically or with changes in ECG, receiving regular medication for 133 hypertension, hyperlipidemia or diabetes, or having been diagnosed with serious non-CVD). The

134 last group was named 'signs of CVD' while the majority of the conditions that the men had were 135 cardiovascular diseases or related to the metabolic system. 


\section{Physical functioning}

138 In the year 2000 at a mean age of 73.3 (SD 4.1) years, physical functioning was assessed using 139 ten items included in the physical functioning domain from the validated RAND-36 Health 140 Survey (Version 1.0) (identical with the Short Form SF-36). ${ }^{25,26}$ Cohort members were asked to 141 what extent their health limited daily activities such as walking two or half a kilometer or 100

142 meters or climbing 1 or several flight of stairs. If the participants had no difficulties, some

143 difficulties or they were unable to perform a task, these were coded as 100,50 and 0 , 144 respectively, they were summed up and divided by 10 . Scores range from 0 to 100 and a higher 145 score indicated better physical functioning. For each data collection wave, 7 out of the 10 146 physical functioning items were required for the score to be calculated (and in that case the

147 summed score was divided by the respective number of answered items). The proportion of 148 those who had data missing on three items at most ranged between 1.0 and $1.7 \%$ across the

149 four data collection waves and when considering all four follow-ups the percentage of those with 7 out of 10 answers for each follow-up we were able to include 48 persons (3.1\%).

\section{Health characteristics in midlife and old age}

153 The cohort members were inquired in 1974 about self-rated health with response alternatives:

154 very good, fairly good, average, fairly poor and very poor. For the analyses, two latter ones were 155 coded into one category "poor" due to few cases in the very poor category. ${ }^{27}$ In the year 2000, 156 the participants were asked about physician-diagnosed illnesses in a mailed questionnaire. The men who reported having at least one of the following diseases: stroke, transient ischemic

158 attack, high blood pressure, coronary artery disease, heart failure, or dysfunction in 
160 were retrieved from the Finnish Population Register Center for the entire cohort between 1974 161 and 2010.

\section{Statistical methods}

164 We identified different physical functioning trajectories by fitting latent class growth mixture models (LGM M ) to all available physical functioning data of the 1560 cohort members from the years 2000, 2003, 2007 and 2010 using M plus version 7.0.28 In the analyses, we used LGM M with Full Information Maximum Likelihood, in order to capture unobserved subpopulations (latent groups) in all available data with similar physical functioning trajectories, but which were distinct across the latent groups over the follow-up time. Grouping was based on the likelihood of the membership calculated for each individual's own trajectory. Each latent group had their

171 own growth parameters, intercept (indicating similar trajectories over time) and slope

172 (indicating changes in physical functioning scores over time). We estimated the quadratic and

173 cubic shapes of the trajectories in order to identify all potential differences in the development 174 of physical functioning. We used several model fit indices to determine the optimal number of 175 latent groups. ${ }^{28}$ For Bayesian Information Criterion (BIC) and Akaike Information Criterion (AIC), 176 lower values indicate a better fit of the model. Clarity of classification into trajectory classes 177 was assessed with 1) high percentage of individuals falling into the latent class based on the 178 posterior probabilities (indicates the probability of a participant belonging in a given trajectory

179 class) and 2) high model entropy (an aggregate of posterior probabilities), which ranges 180 between 0 and 1, with values near 1 indicating clear classification.

182 The conceptual model for investigating the association between CVD status in midlife and 183 physical functioning trajectories in old age is presented in Figure 2. We constructed a competing 
184 risks multinomial regression model to model the risk related to physical functioning trajectory 185 class membership while simultaneously accounting for mortality risk during the physical 186 functioning assessments between the years 2000 and 2010. Kaplan-M eier survival curves did 187 not cross for the major part of time thus supporting proportionality. The proportionality of 188 hazards was tested using the scaled Schoenfeld residuals, where non-significant p-values lend 189 support for the proportionality assumption. The proportionality was supported for all 190 covariates with an effect in the mortality part of the model: CVD status in y. 1974 (high risk vs. 191 rest, $p=0.575$; sick vs. rest, $p=0.797)$, self-rated health in y. $1974(p=0.629)$, CVD in y. 2000 $192(p=0.669)$ and the global estimate of proportionality $(p=0.875)$. We estimated unstandardized

193 regression coefficients $(\beta)$, their mean errors (SE) and related $p$-values for the associations. 194 Based on the proportional hazards model, the latent effect of excess mortality risk was used to 195 adjust the physical functioning trajectory class for mortality risk. In addition, the model was 196 adjusted for birth year, self-rated health in midlife and self-reported CVD in the year 2000. 71 197 (4.6\%) individuals had missing data for self-rated health, which were imputed using multiple imputation in SPSS with data on all intact variables included in the prediction of missing values. Significance level was set at 0.05 and tests were two sided.

200

\section{RESULTS}

202

The model fit indices used to determine the best model fit for the physical functioning data in the 10-year follow-up indicating the optimal number of latent classes, i.e. physical functioning 204 trajectories, are presented in the Supplementary Table S1. BIC was lowest for the five-class solution. Average membership probabilities in the five latent classes ranged between 0.78 and 0.88 , while model entropy was 0.71 indicating reasonable classification clarity. The five physical 
208

class), 'high stable' (32\%), 'high and declining' (29\%), 'intermediate and declining' (23\%), and

209

210 trajectory are presented in Supplementary Figure S1.

211

212 There were statistically significant differences in the characteristics of the cohort members 213 across the physical functioning trajectories presented in Table 1. The men classified into the 'intact' and 'high stable' trajectory were younger at baseline, 45.2 (SD 3.6) and 46.5 (SD 3.9) 215 years, respectively, whereas those in the 'consistently low' trajectory were the oldest 49.0 (3.8) years. The proportion of men with signs of CVD was higher in the poorer physical functioning trajectories (7.7\% in the 'intact' vs. $33.7 \%$ in the 'consistently low' trajectory). There were also differences for self-rated health in midlife across the trajectories; of those in the 'intact' trajectory, $44.0 \%$ rated their health very good or fairly good, whereas the corresponding 220 proportion was $19.0 \%$ in the 'consistently low' trajectory. The prevalence of CVD in the year 2000 was $31.0 \%$ for the men assigned to the 'intact' trajectory and increased in the poorer physical functioning trajectories being $85.4 \%$ in men belonging to the 'consistently low' trajectory. Out of the 1560 cohort members, 539 (34.6\%) died between the years 2000 and 2010. M ortality during ten years was higher among those who were classified into the poorer physical functioning trajectories $(17.6 \%$ in the 'intact' trajectory vs. $84.3 \%$ in the 'consistently low' trajectory).

The results of the associations between midlife CVD status and physical functioning trajectories 230 in old age for the competing risk multinomial regression models are presented in Table 2. 
232 classified into the 'intact' (fully adjusted $\beta-3.98$, SE 2.0, $p=0.046$ ) trajectory relative to

233 'consistently low' physical functioning trajectory. In terms of effect size, the associations were

234 parallel for the 'high stable' and 'high and declining' trajectories but not statistically significant.

235 Compared to the men with low CVD risk, those with signs of CVD in midlife were also less likely

236 to be classified into the 'intact', 'high stable' and 'high and declining' physical functioning

237 trajectory relative to the 'consistently low' trajectory, all p-values $\varangle$ $\varangle 18$. The association was

238 also parallel but statistically non-significant for the 'intermediate and declining' trajectory. The

239 proportion of those who died during the follow-up increased gradually with declining physical

240 functioning trajectories. The prevalence of mortality was lowest among those in the 'intact'

241 trajectory (approximately 18\%) and highest among those in the 'intermediate and declining'

242 (54\%) and 'consistently low' trajectories (84\%), p-value $\varangle 0.001$.

DISCUSSION

245 We identified five distinct physical functioning trajectories during a 10-year period in a cohort of old business executives who have been followed up from midlife. Albeit around forty percent of the men were classified into the 'intact' or 'high stable' physical functioning trajectory, a fair number of cohort members showed signs of declining physical functioning which progressed during the follow-up period in old age. A clinically significant decrease of 5 or more points ${ }^{29}$ in the RAND-36 physical functioning sub-category score was observed in all other trajectories expect for the 'intact' trajectory. A more favorable CVD profile in midlife was associated with 252 better development of physical functioning in old age. Compared to low CVD risk, those with 253 high CVD risk or signs of CVD were less likely to follow one of the four more favorable physical 254 functioning trajectories. The association persisted after adjustment for CVD in old age and also 255 after accounting for mortality as a competing risk. Our findings provide new evidence on the 
256

long-term association between modifiable CVD risk factors and subsequent patterns of physical

257 functioning.

258

259

260

Previous studies have found that higher CVD risk scores, indicating impaired cardiovascular health, are related to poorer subsequent physical functioning. ${ }^{16-19}$ However, to the best of our 261 knowledge, there are no previous studies on the patterns of physical functioning that are related to earlier CVD status. In the present study, high CVD risk in midlife decreased the 263 probability of being assigned to a physical functioning trajectory that was intact across the 10year follow-up of physical functioning in old age. For the men with signs of CVD in midlife, i.e. CVD diagnosed either clinically or with changes in ECG, receiving regular medication for 266 in midlife which may have later led to functional decline. ${ }^{30}$ physiological changes related to disease processes and geriatric syndromes. ${ }^{6,31}$ For example, smoking and hypertension may lead to peripheral artery disease which predisposes to declining

277 physical functioning. ${ }^{32}$ Furthermore, damage to the musculoskeletal and peripheral nervous 278 systems start to occur well before the consequences for physical functioning can be detected.

279 Evidence that the onset of the chronic disease burden starts already early on in life is growing. ${ }^{33}$ 
280

281

282

283

284

285

286

287

288

289

290

291

292

293

294

295

296

297

298

299

300

301

302

303

Notably, early detection of risk factors that are known to subsequently be related to disability later in life help to identify individuals who potentially stand to gain from preventive health care measures. ${ }^{30}$ Modelling physical functioning trajectories provide more knowledge on the progress of limitation and the timing of preventive measures for maintaining physical capability.

The strengths of our study include the well-characterized sample of businessmen and executives who came from a homogenous background and who have been followed up across several decades. Midlife cardiovascular status was determined based on measurement/assessment of several CVD risk factors which is similar to other established CVD risk scores such as the Framingham Risk Score. ${ }^{34}$ Physical functioning was assessed using the ten items included in the sub-scale of physical functioning from the validated RAND-36 Health Survey questionnaire ${ }^{25}$ and having several data collection waves allowed for modeling trajectories over time. GMM analyses are data-driven and a person-centered approach to classifying study participants into sub-groups in a post-hoc manner. The method can be used to describe differences in longitudinal change between and within the unobserved groups. We used a competing risk model to account for mortality that occurred during the 10-year physical functioning follow-up among the old businessmen.

Some limitations of the study should be recognized. The cohort comprised of men only and included individuals belonging to the highest socioeconomic strata which limits generalizability. The business executives and managers at that time worked typically long hours and the work was often stressful. These aspects of work have been shown to contribute to a higher prevalence of CVD. ${ }^{35}$ We did not have the same measures of CVD risk available in old age that we had in midlife and were not able to investigate the long-term association between CVD risk 
304

305

306

307

308

309

310 311 as frailty. ${ }^{36}$

312

313 In conclusion, in a cohort of older businessmen and executives, midlife cardiovascular status 314 physical functioning in older age. was related to physical functioning patterns in old age which varied greatly among the men.

\section{Trajectories that indicate stability/maintenance of physical functioning into old age are markers} for healthy ageing and quality of life and important outcomes in terms of the individual's ability to lead an independent and active life. Our results indicate that CVD risk status in midlife is a useful measure in determining the risk of poor physical functioning decades later. Furthermore, intervening in these modifiable risk factors already in midlife might help mitigate decline in

status and later outcomes. During the follow-up of physical functioning between the years 2000 and 2010, mortality was relatively high. Using a maximum likelihood method in the GM M analyses, which uses all existing information and does not require complete data, we accounted for non-random missingness related to mortality. We also further accounted for mortality during the follow-up by using a competing risk model in the multinomial regression analyses. We did not have data on physical functioning in midlife and thus adjusted for self-rated health, which is a good general measure of health and is related to adverse outcomes in later life such 


\section{Author contributions}

330 M BvB drafted the paper, analyzed the data, designed the study; MJH interpreted the data,

331 designed the study, revised the paper critically for important intellectual content; $\pi$

332 interpreted the data, designed the study, revised the paper critically for important intellectual

333 content; KP interpreted the data, designed the study, revised the paper critically for important

334 intellectual content; SS interpreted the data, designed the study, revised the paper critically

335 for important intellectual content; TS responsible for data acquisition, interpreted the data,

336 designed the study, revised the paper critically for important intellectual content.

337

338 Sponsor's Role

339 The funders has no role in the design, methods, analysis and preparation of the paper. The

340 Academy of Finland supported M BvB grant no. 257239 and EU H2020-PHC-2014-DynaHealth

341 grant no. 633595. The Academy of Finland supported TT grant no 286536. The Academy of

342 Finland supported SS grant no 286294, 294154 and 319246.

343

344

345 


\section{LEGENDS}

347

348 Figure 1 Study flowchart.

349

350 Figure 2 Conceptual model for assessment of midlife CVD status and physical functioning

351 trajectories in old age when accounting for birth year, self-rated health in midlife, CVD in older

352 age and excess mortality risk. Squares are observed values and circles are latent values.

353

354 Figure 3 Identified physical functioning trajectories over the 10-year follow-up from the year

3552000 to 2010.

356

357 Supplementary Figure S1 Individual observations belonging to each physical functioning

358 trajectory.

359

360 Supplementary Table S1. M odel Fit Statistics, Group Sizes and Average Latent Class

361 Probabilities for M ost Likely Class Membership.

362

363 


\section{REFERENCES}

365

366

367

368

369

370

371

372

373

374

375

376

377

1. United Nations, Department of Economic and Social Affairs, Population Division. World population prospects: The 2015 revision, key findings and advance tables. Working paper no. ESA/P/WP.241. New York, US: United Nations; 2015.

2. Guralnik JM, Simonsick EM, Ferrucci L, et al. A short physical performance battery assessing lower extremity function: Association with self-reported disability and prediction of mortality and nursing home admission. J Gerontol 1994;49:85-94.

3. Guralnik JM, Ferrucci L, Simonsick EM, Salive ME, Wallace RB. Lower-extremity function in persons over the age of 70 years as a predictor of subsequent disability. N Engl J M ed 1995;332:556-561.

\section{4. von Bonsdorff M, Rantanen T, Laukkanen P, Suutama T, Heikkinen E. M obility limitations and} cognitive deficits as predictors of institutionalization among community-dwelling older people. Gerontology 2006;52:359-365.

5. Cesari M, Onder G, Zamboni V, et al. Physical function and self-rated health status as predictors of mortality: Results from longitudinal analysis in the ilSIRENTE study. BM C Geriatr 2008;8:34-2318-8-34.

6. Rosso AL, Eaton CB, Wallace R, et al. Combined impact of geriatric syndromes and cardiometabolic diseases on measures of functional impairment. J Gerontol A Biol Sci M ed Sci 2011;66:349-354.

7. WHO. Active ageing. A policy Framework.

http://whqlibdoc.who.int/hq/2002/who_nmh_nph_02.8.pdf; 2002.

8. Chang M, Saczynski JS, Snaedal J, et al. M idlife physical activity preserves lower extremity function in older adults: Age Gene/ environment Susceptibility-Reykjavik Study. J Am Geriatr Soc 2013;61:237-242.

9. Strand BH, M ishra G, Kuh D, Guralnik JM, Patel KV. Smoking history and physical performance in midlife: Results from the British 1946 birth cohort. J Gerontol A Biol Sci Med Sci 2011;66:142-149. 
386

387

388

389

390

391

392

393

394

395

396

397

398

399

400

401

402

403

404

405

406

407

10. Gopinath B, Russell J, Flood VM , Burlutsky G, M itchell P. Adherence to dietary guidelines positively affects quality of life and functional status of older adults. J Acad Nutr Diet 2014;114:220-229.

11. Rosano C, Longstreth WT,Jr, Boudreau R, et al. High blood pressure accelerates gait slowing in wellfunctioning older adults over 18-years of follow-up. J Am Geriatr Soc 2011;59:390-397.

12. Stenholm S, Sainio P, Rantanen T, et al. High body mass index and physical impairments as predictors of walking limitation 22 years later in adult Finns. J Gerontol A Biol Sci Med Sci 2007;62:859865.

13. Chakravarty EF, Hubert HB, Krishnan E, Bruce BB, Lingala VB, Fries JF. Lifestyle risk factors predict disability and death in healthy aging adults. Am J Med 2012;125:190-197.

14. Koster A, Penninx BW, Newman AB, et al. Lifestyle factors and incident mobility limitation in obese and non-obese older adults. Obesity (Silver Spring) 2007;15:3122-3132.

15. Sabia S, Elbaz A, Rouveau N, Brunner EJ, Kivimäki M, Singh-M anoux A. Cumulative associations between midlife health behaviors and physical functioning in early old age: A 17-year prospective cohort study. J Am Geriatr Soc 2014;62:1860-1868.

16. Elbaz A, Shipley MJ, Nabi H, Brunner EJ, Kivimäki M, Singh-M anoux A. Trajectories of the Framingham general cardiovascular risk profile in midlife and poor motor function later in life: The Whitehall II Study. Int J Cardiol 2014;172:96-102.

17. Jin Y, Tanaka T, Ma Y, Bandinelli S, Ferrucci L, Talegawkar SA. Cardiovascular health is associated with physical function among older community dwelling men and women. J Gerontol A Biol Sci Med Sci. 2017;72:1710-1716.

18. Windham BG, Harrison KL, Lirette ST, et al. Relationship between midlife cardiovascular health and late-life physical performance: The ARIC study. J Am Geriatr Soc 2017;65:1012-1018. 
408 19. Dhamoon MS, Dong C, Elkind MS, Sacco RL. Ideal cardiovascular health predicts functional status

409 independently of vascular events: The Northern Manhattan Study. J Am Heart Assoc

$410 \quad 2015 ; 4: 10.1161 / J A H A .114 .001322$.

411 20. Hardy SE, Dubin JA, Holford TR, Gill TM. Transitions between states of disability and independence

412 among older persons. Am J Epidemiol 2005;161:575-584.

413 21. Strandberg TE, Salomaa V, Strandberg AY, et al. Cohort profile: The Helsinki Businessmen Study 414 (HBS). Int J Epidemiol 2016;45:1074.

415 22. M iettinen TA, Huttunen JK, Naukkarinen V, et al. M ultifactorial primary prevention of

416 cardiovascular diseases in middle-aged men. Risk factor changes, incidence, and mortality. JAM A

$417 \quad 1985 ; 254: 2097-2102$.

418 23. Gray D \& Fujioa K. Use of relative weight and body mass index for the determination of adiposity. J

419 Clin Epidemiol. 1991;44:545-50

420 24. Strandberg TE, Salomaa VV, Naukkarinen VA, Vanhanen HT, Sarna SJ, M iettinen TA. Long-term

421 mortality after 5-year multifactorial primary prevention of cardiovascular diseases in middle-aged 422 men. JAMA 1991;266:1225-1229.

423 25. Aalto AM, Aro S, Aro AR, Mähönen M. RAND 36-item Health Survey 1.0. Finnish version on the 424 health-related quality of life questionnaire. Helsinki, Finland: Stakes; 1995.

425 26. Hays RD, Sherbourne CD, M azel RM. The RAND 36-item Health Survey 1.0. Health Econ 1993;2:217426227.

427 27. Huohvanainen E, Strandberg AY, Stenholm S, Pitkälä KH, Tilvis RS, Strandberg TE. Association of 428 self-rated health in midlife with mortality and old age frailty: A 26-year follow-up of initially healthy 429 men. J Gerontol A Biol Sci Med Sci 2016;71:923-928. 
28. M uthen,L.K,M uthen,B.O. M plus user's guide. Los Angels, CA: M uthen \& Muthen; 1998.

431

432

433

434

435

436

437

438

439

440

441

442

443

444

445

29. Angst F, Aeschlimann A, Stucki G. Smallest detectable and minimal clinically important differences of rehabilitation intervention with their implications for required sample sizes using W OM AC and SF36 quality of life measurement instruments in patients with osteoarthritis of the lower extremities. Arthritis Rheum 2001;45:384-91.

30. Ferrucci L, Cooper R, Shardell M, Simonsick EM, Schrack JA, Kuh D. Age-related change in mobility: Perspectives from life course epidemiology and geroscience. J Gerontol A Biol Sci M ed Sci 2016;71:1184-1194.

31. Strandberg TE, Pitkälä KH, Tilvis RS, O'Neill D, Erkinjuntti TJ. Geriatric syndromes-vascular disorders? Ann Med 2013;45:265-273.

32. M cDermott M M , Liu K, Greenland P, et al. Functional decline in peripheral arterial disease: Associations with the ankle brachial index and leg symptoms. JAMA 2004;292:453-461.

33. Belsky DW, Caspi A, Houts R, et al. Quantification of biological aging in young adults. Proc Natl Acad Sci U SA 2015;112:E4104-110.

34. D'Agostino RB S, Vasan RS, Pencina MJ, et al. General cardiovascular risk profile for use in primary care: The Framingham Heart Study. Circulation 2008;117:743-753.

35. Nyberg ST, Fransson El, Heikkilä K, et al. Job strain and cardiovascular disease risk factors: M etaanalysis of individual-participant data from 47,000 men and women. PLoS One 2013;8:e67323.

36. Stenholm S, Kivimäki M, Jylhä M, et al. Trajectories of self-rated health in the last 15 years of life by cause of death. Eur J Epidemiol 2016;31:177-185. 
Table 1 Characteristics of the Cohort M embers According to Physical Functioning Trajectories

\begin{tabular}{|c|c|c|c|c|c|c|}
\hline & \multicolumn{5}{|c|}{ Physical functioning trajectories* } & \multirow{3}{*}{$p$-value } \\
\hline & Intact & High stable & High and & Intermediate and & Consistently low & \\
\hline & & & $\begin{array}{c}\text { declining } \\
n=440\end{array}$ & $\begin{array}{c}\text { declining } \\
n=371\end{array}$ & & \\
\hline Birth year, \% & & & & & & $\varangle 0.001$ \\
\hline $1919-1925$ & 20.4 & 31.1 & 40.2 & 54.2 & 53.9 & \\
\hline 1926-1933 & 79.6 & 68.9 & 59.8 & 45.8 & 46.1 & \\
\hline Age in 1974, years, mean (SD) & $45.1(3.6)$ & $46.5(3.9)$ & $47.6(3.9)$ & $48.5(3.8)$ & $49.0(3.8)$ & $\varangle 0.001$ \\
\hline CVD status in $1974, \%$ & & & & & & $\varangle 0.001$ \\
\hline Low risk & 43.0 & 33.6 & 32.7 & 18.6 & 13.5 & \\
\hline High risk & 49.3 & 51.5 & 51.1 & 57.1 & 52.8 & \\
\hline Signs of CVD & 7.7 & 14.9 & 16.2 & 24.3 & 33.7 & \\
\hline Self-rated health in $1974, \%$ & & & & & & $\varangle 0.001$ \\
\hline Very good & 13.9 & 3.9 & 3.8 & 1.7 & 0.0 & \\
\hline Fairly good & 40.1 & 35.1 & 32.9 & 22.7 & 19.0 & \\
\hline Average & 40.9 & 50.8 & 52.6 & 54.3 & 51.2 & \\
\hline Poor & 5.1 & 10.2 & 10.7 & 21.3 & 29.8 & \\
\hline CVD* in year $2000, \%$ & 31.0 & 52.1 & 62.7 & 69.0 & 85.4 & $\varangle 0.001$ \\
\hline Died between 2000 and 2010, \% & 17.6 & 21.4 & 28.9 & 54.2 & 84.3 & $\varangle 0.001$ \\
\hline
\end{tabular}

$\mathrm{SD}=$ standard deviation

${ }^{*}$ Assessed between 2000 and 2010

${ }^{\dagger}$ CVD included self-reported prevalence of stroke, transient ischemic attack, high blood pressure, coronary artery disease, heart failure, or dysfunction in cerebrovascular or lower extremity circulation. 
Table 2 Unstandardized Betas, Standard Errors and P-values for Path Coefficients of M odels for M idlife CVD Status Predicting Physical Functioning Trajectories in Old Age in the Helsinki Businessmen Study

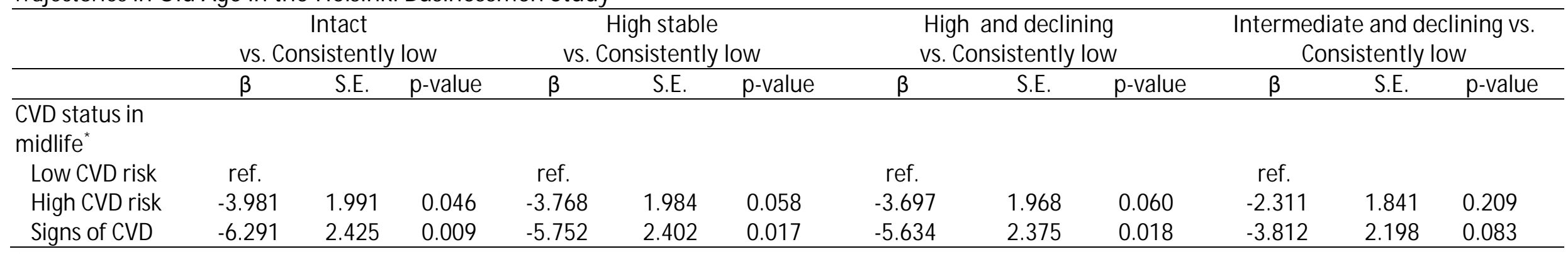

CVD=cardiovascular disease

${ }^{*}$ Estimated with adjustment for birth year, self-rated health in midlife, CVD status in the year 2000 and excess mortality risk between 2000 and 2010. 
Figure 1

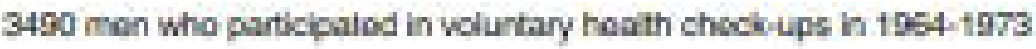

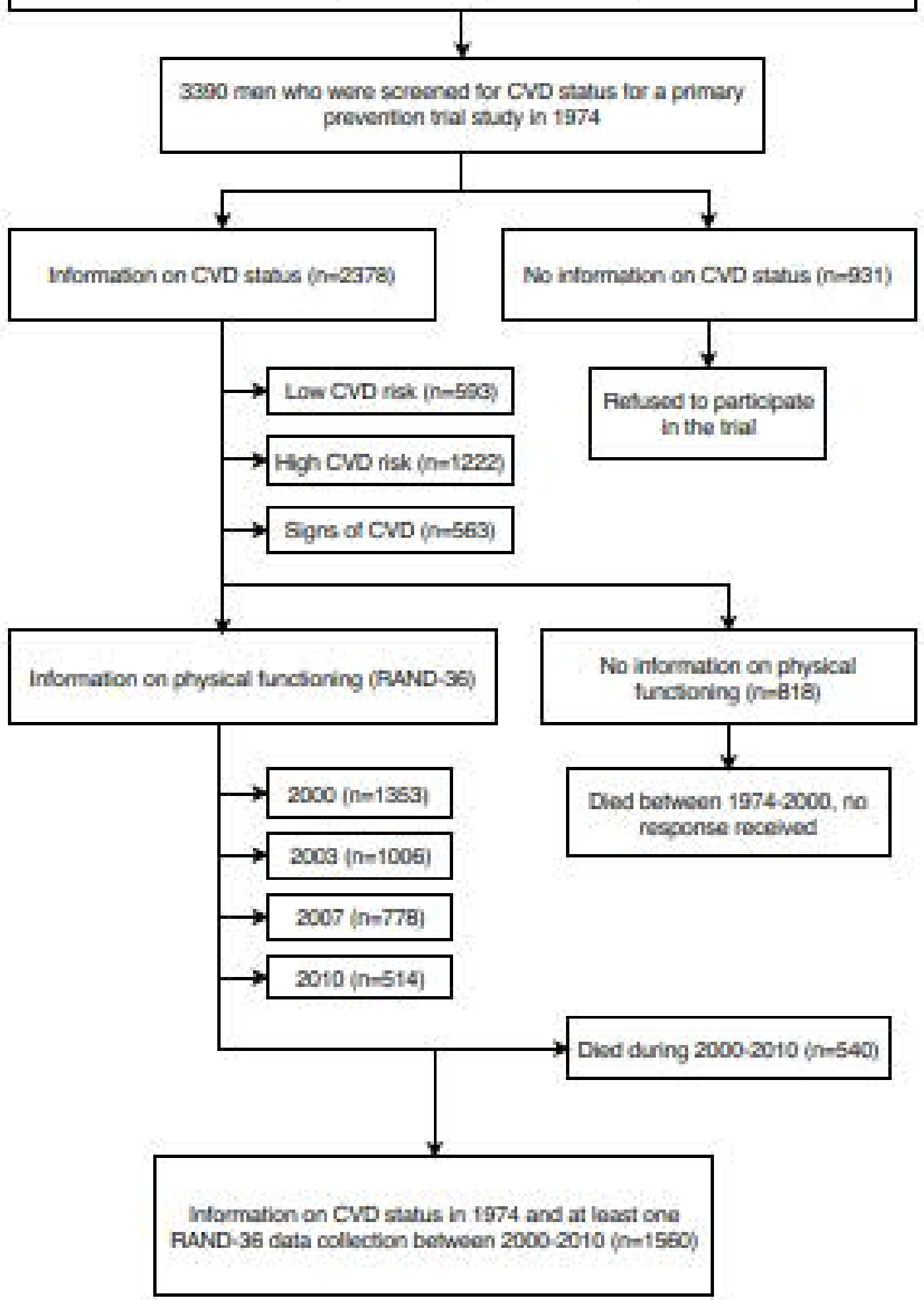


Figure 2.

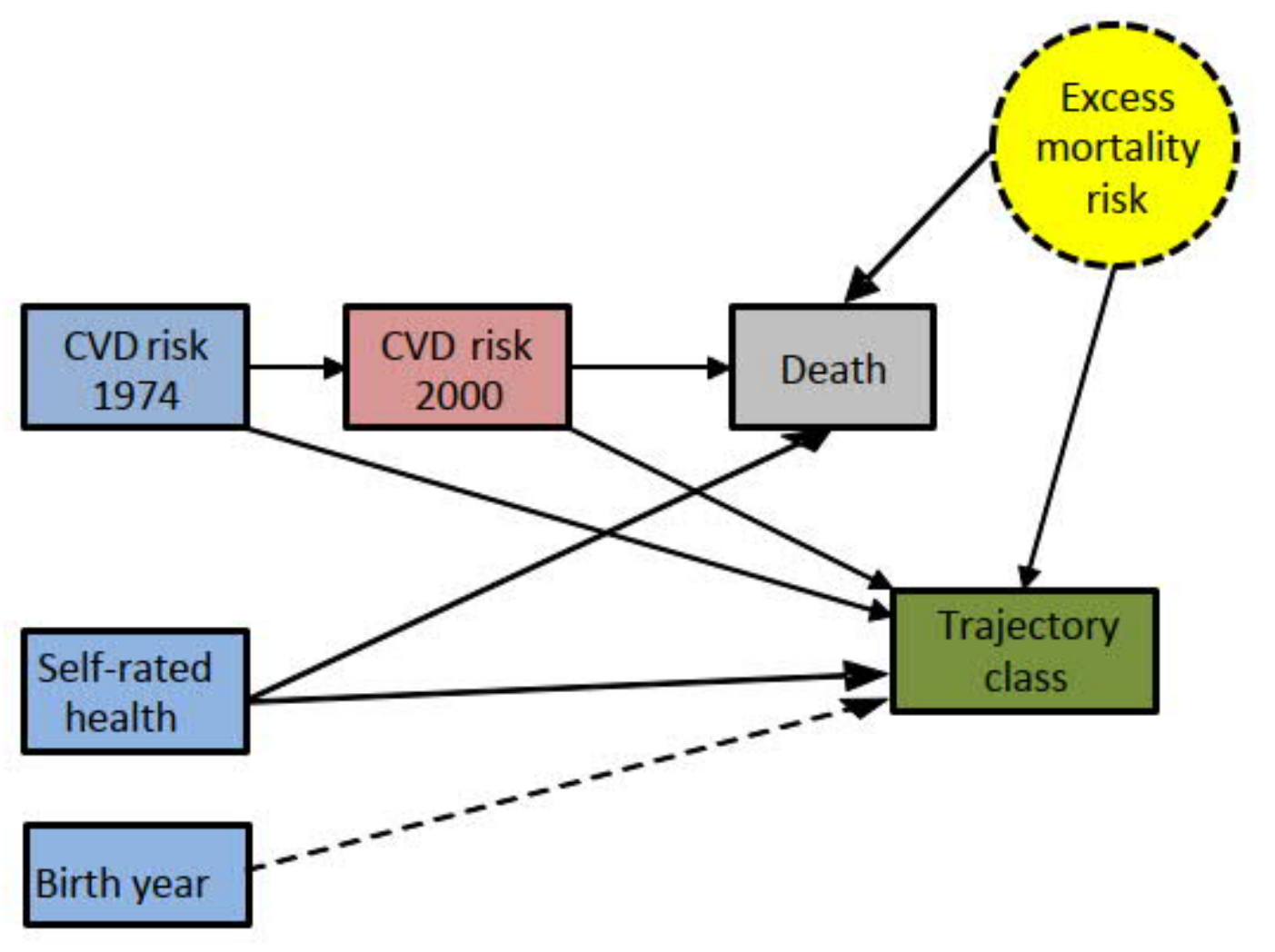


Figure 3

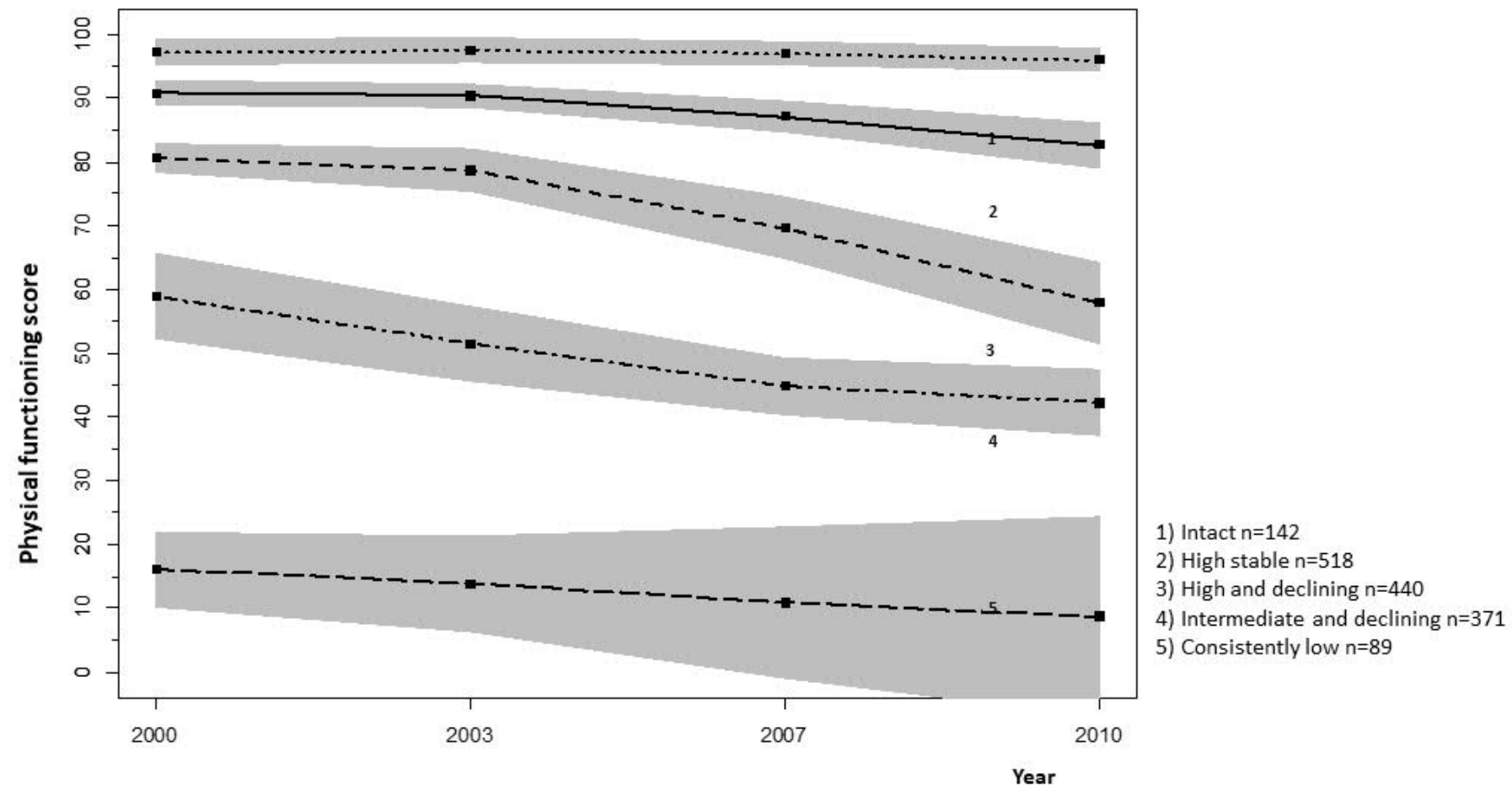


Supplementary Table S1. M odel Fit Statistics, Group Sizes and Average Latent Class Probabilities for M ost Likely Class M embership.

\begin{tabular}{|c|c|c|c|c|c|c|c|c|c|c|c|c|c|}
\hline \multirow[b]{2}{*}{ Classes } & \multirow[b]{2}{*}{ LL } & \multirow[b]{2}{*}{ Scaling } & \multirow[b]{2}{*}{$\begin{array}{c}\text { Free } \\
\text { parameters }\end{array}$} & \multicolumn{3}{|c|}{ Information criteria } & \multirow[b]{2}{*}{ Entropy } & \multicolumn{6}{|c|}{$\begin{array}{l}\text { Group size (Average latent class probability } \\
\text { for most likely latent class membership) }\end{array}$} \\
\hline & & & & AIC & BIC & $\mathrm{aBIC}$ & & $\mathbf{n}_{\mathbf{l}}$ & $\mathbf{n}$ & $\mathbf{n}_{\mathbf{B}}$ & $\mathbf{n}_{4}$ & $\mathbf{n}_{\mathbf{5}}$ & $\mathbf{n}_{\mathbf{6}}$ \\
\hline 1 & -21939 & 1.88 & 13 & 43904 & 43977 & 43935 & 1.000 & $\begin{array}{c}1991 \\
(1.00)\end{array}$ & & & & & \\
\hline 2 & -20815 & 1.26 & 27 & 41684 & 41835 & 41749 & 0.742 & $\begin{array}{c}960 \\
(0.95)\end{array}$ & $\begin{array}{c}1031 \\
(0.91)\end{array}$ & & & & \\
\hline $3^{b}$ & -20597 & 1.49 & 38 & 41270 & 41483 & 41362 & 0.712 & $\begin{array}{c}742 \\
(0.93)\end{array}$ & $\begin{array}{c}818 \\
(0.84)\end{array}$ & $\begin{array}{c}431 \\
(0.81)\end{array}$ & & & \\
\hline $4^{c}$ & -20495 & 1.31 & 49 & 41087 & 41361 & 41206 & 0.691 & $\begin{array}{c}610 \\
(0.78)\end{array}$ & $\begin{array}{c}198 \\
(0.80)\end{array}$ & $\begin{array}{c}517 \\
(0.92)\end{array}$ & $\begin{array}{c}666 \\
(0.78)\end{array}$ & & \\
\hline $5^{d}$ & -20453 & 1.24 & 54 & 41009 & 41312 & 41140 & 0.712 & $\begin{array}{c}556 \\
(0.78)\end{array}$ & $\begin{array}{c}191 \\
(0.79)\end{array}$ & $\begin{array}{c}461 \\
(0.84)\end{array}$ & $\begin{array}{c}631 \\
(0.78)\end{array}$ & $\begin{array}{c}152 \\
(0.88)\end{array}$ & \\
\hline $6^{e}$ & -20422 & 1.18 & 65 & 40973 & 41337 & 41131 & 0.658 & $\begin{array}{l}535 \\
(0.73)\end{array}$ & $\begin{array}{l}189 \\
(0.78)\end{array}$ & $\begin{array}{c}139 \\
(0.66)\end{array}$ & $\begin{array}{c}619 \\
(0.79)\end{array}$ & $\begin{array}{l}377 \\
(0.66)\end{array}$ & $\begin{array}{c}132 \\
(0.79)\end{array}$ \\
\hline \multicolumn{14}{|c|}{$\begin{array}{l}\text { Note. } L L=\text { loglikelihood, scaling = Robust maximum likelihood scaling factor, } A I C=A \text { kaike information criterion, BIC =Bayesian information } \\
\text { criterion, aBIC = sample size adjusted Bayesian information criterion. } \\
\text { bParameter restrictions in class 3: } \operatorname{var}(Q)=0, \operatorname{cov}(I, Q)=0, \operatorname{cov}(S, Q)=0 \text {. } \\
\text { 'Parameter restrictions in class 2: } \operatorname{var}(Q)=0, \operatorname{cov}(I, Q)=0, \operatorname{cov}(S, Q)=0 \text {, and in class 3: } \operatorname{var}(Q)=0, \operatorname{cov}(I, Q)=0, \operatorname{cov}(S, Q)=0 \text {. } \\
\text { dParameter restrictions in class 2: } \operatorname{var}(Q)=0, \operatorname{cov}(I, Q)=0, \operatorname{cov}(S, Q)=0, \text { and in } \operatorname{class} 3: \operatorname{var}(I)=0, \operatorname{var}(S), \operatorname{var}(Q)=0, \operatorname{cov}(I, Q)=0, \operatorname{cov}(I, S)=0, \\
\operatorname{cov}(S, Q)=0 \text {, and in class 4: intercept }(Q)=0, \operatorname{var}(I)=0, \operatorname{var}(Q)=0, \operatorname{cov}(I, Q)=0, \operatorname{cov}(I, S)=0, \operatorname{cov}(S, Q)=0 \text {. } \\
\text { eParameter restrictions in class }\end{array}$} \\
\hline
\end{tabular}


Supplementary Figure S1
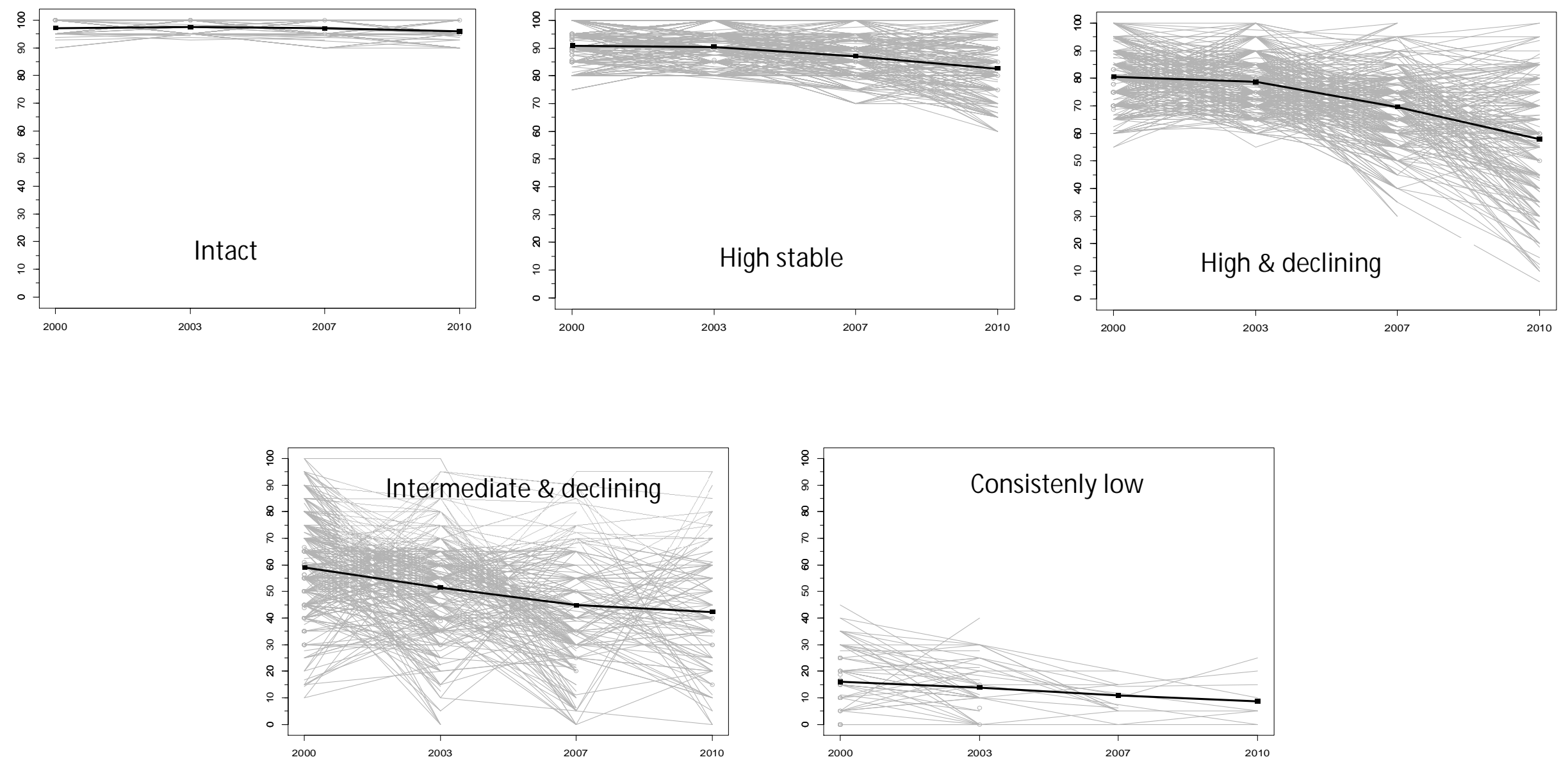